\section{Los códices de la cultura Náhuatl: notas para una valoración}

\author{
Ricardo Molina Verdejo*
}

\begin{abstract}
Afrontar cualquier tema vinculado con las culturas del México prehispánico supone siempre, por decir lo menos, un desafío y -al mismo tiempo- una invitación al asombro. En efecto, sea cual sea el aspecto en el que se pretenda adentrar con el propósito de saber algo más, inevitablemente se encontrarán con cierta frecuencia hechos, situaciones o problemas que sorprenderán al lector o investigador por su singularidad.

Asumiendo que la información que se conoce
\end{abstract}

\footnotetext{
Docente-Investigador Instituto de Ciencias Sociales, Universidad Austral de Chile.
}

acerca de los pueblos del valle de México es bastante, aunque nunca suficiente, de manera obligada se gatilla la ansiedad por saber más. Al rememorar sobre los estudios existentes en torno a las más antiguas culturas de la Historia Universal localizadas tradicionalmente en las regiones del Trigis y Eufrates, o valle del Nilo, "cunas" de la civilización humana, una característica en común asoma de inmediato; sabemos de ellas. Esta conclusión en nada nueva ni espectacular lleva, eso sí, a preguntarse acerca de las razones del porqué han llegado hasta nosotros. Las respuestas podrían ser variadas aunque dentro de una tónica próxima, ya atribuyendo méritos a las ciencias históricas, arqueológicas, antropológicas u otras disciplinas afines al haber traído hasta el presente las maravillas que miles de seres humanos construyeron por siglos.

Nada más cierto, el trabajo efectuado por especialistas diversos cuya preocupación profesional ha sido la reconstrucción del pasado en esa permanente búsqueda de datos, fuentes o restos en la idea de ir poco a poco aportando a los muchos vacios cognitivos existentes, han contribuido con lo suyo. Pero cabe, aunque obvia, la siguiente reflexión: si desde el presente existe el vivo interés por estudiar el pasado, da lugar a pensar sobre si los hombres de aquellos lejanos tiempos no tendrían la intención de comunicar sus vivencias perpetúandolas para el futuro a través de vestigios físicos o de la propia escritura. La respuesta es clara. Que duda cabe o puede haber si los mesopotánicos de treinta siglos a.c. dibujaron o escribieron en las tabletas de barro o los egipcios en la piedra con el fin de establecer una memoria que pudiera sobrevivir en el tiempo. En este sentido parece haber una constante en el hombre de todas las épocas, bajo el convencimiento de "seguir viviendo" al proyectar sus pensamientos y obras hacia adelante, consigue dejar los recuerdos para el futuro. 
Siendo las culturas mesoamericanas muy posteriores en su aparición y evolución a las recién citadas, cuando alcanzaron grados de desarrollo superiores aparecen también formas de preocupación por registrar sus experiencias, pensando en perpetuarlas mirando hacia las generaciones venideras. Esta voluntad la encontramos con peso y fuerza en la cultura náhuatl.

La intención por dejar constancia de los hechos de su presente por la vía del registro de ellos en hermosos como dramáticos poemas, o en artísticos códices, deja a la vista un especial interés y dedicación al respecto. Construir una memoria colectiva revela un alto nivel de reflexión y conciencia en torno a la estimación de sí mismos. Por este motivo, resulta admirable advertir la forma cómo los antiguos habitantes de México lo realizaron en plena consonancia a su mundo de creencias y a los hechos que al momento vivían.

Considerando las estimaciones planteadas, el propósito de este trabajo es simplemente aproximarnos a una valoración de los códices y textos nahuas, tanto desde la perspectiva de sus creadores como de los investigaciones más recientes.

\section{LOS CODICES Y LA IMPORTANCIA DEL PASADO}

Gran parte de los códices nahuas que hoy se conocen fueron elaborados durante el siglo XVI, es decir, dentro del período hispánico o colonial. Sin embargo, sin prejuicios de la sobrevivencia de unos pocos prehispánicos, la totalidad de ellos fueron confeccionados a la usanza tradicional y -por lo tanto- utilizando las mismas técnicas de los antiguos. Esto se explica por el simple hecho de que quienes fueron sus artífices, eran los herederos directos de la cultura náhuatl y que ha- lar, aprendieron el español como segunda lengua.

Tomando el caso, por ejemplo, de los informantes de Sahagún ${ }^{1}$, se trataba de indígenas que poseían el conocimiento del pasado y la sabiduría cultural náhuatl, los que ante la llamada de Fray Bernardino acudieron a responder sus preguntas apoyándose en libros de pinturas y recuerdos recibidos por la tradición y la historia.

Siguiendo al autor mexicano Miguel León Portilla, los antiguos habitantes aborígenes tenían incorporado en su acervo la preocupación por recordar el pasado como por registrarlo para su conservación. Dentro de su propia lengua habian dos palabras que designaban los respectivos conceptos: Itoloca o "lo que se dice de alguien o de algo", y Xiuhámatl, equivalente a "anales o códices de años" 2. En suma, se trataría precisamente de la Tradición y de la Historia consideradas el análisis obliga- en términos relativos por tratarse de palabras de una cultura lejana y distinta. La primera, trasmitida básicamente en forma oral por generaciones. La segunda, vinculada a la anterior, escrita y representada en los códices por dibujos, pinturas y glifos.

En consecuencia, son los códices los que ha guardado el más valioso tesoro de la cultura náhuatl. Por lo demás, la relevancia que éstos tenían para los habitantes del México Antiguo queda de manifiesto tras comprobar la existencia de las Amoxcalli o "casas de códices", lugares en donde los escribas trabajaban en función de elaborar o copiar libros o códices. Estos funcionarios denominados Tlacuiloani o Tlacuilo, tenian

Informantes de Sahagún. Códice Matritense de la Real Academia de la Historia. También en el Códice Florentino. León Portilla, Miguel. Los Antiguos Mexicanos a través de sus crónicas y cantares. Fondo de Cultura Económica. México, 1961. Cap. II, pp 48 - 75. 
una alta consideración social y se dedicaban también a funciones de observación astronómica y contabilidad cronológica. De manera especial dominaban las técnicas para la fabricación de papel, preparación de cueros de venados o cortezas vegetales con el propósito de contar con material para los códices ${ }^{3}$.

Junto a los escribas existían otros personeros aun mucho más importantes y anteriores, los Tlamatini o "los sabedores de cosas", en una palabra los sabios. Estos mismos habían recibido la denominación de Amoxhuaques o "poseedores de códices" ${ }^{4}$. Según parece ya estaban con los más antiguos, puesto que Bernardino de Sahagún al preguntar acerca del origen de los mexicanos, sus informantes le refirieron respecto de un mítico sitio denominado Tamoanchan o "nosotros buscamos nuestra casa", aludiendo así al lugar de partida de la mítica peregrinación hacia el Golfo de México y luego al valle central. La respuesta, como asimismo la presencia de éstos sabios y su destino posterior, quedan a la vista en parte de un poema transcrito por el fraile;

"Y alli en Tamoanchan también estaban los sabedores de cosas

los llamados poseedores de códices.

Pero éstos no duraron mucho tiempo, los sabios luego se fueron

otra vez se embarcaron,

y llevaron consigo lo negro y lo rojo,

los códices y pinturas

se lievaron todas las artes de los toltecas,

la música de las flautas...

Dicen que les venía hablando su dios...

$Y$ cuando se fueron,

3 Alcina Franch, José. Códices Mexicanos. Colección MAPFRE. Madrid, 1992. Pág. 60.

4 León Portilla, Miguel, Op. Cit. Cap. II, Pág. 49. se dirigieron hacia el rumbo del rostro del Sol.

Se llevaron la tinta negra y roja,

los códices y las pinturas,

se llevaron la sabiduria,

todo tomaron consigo,

los libros de cantos

y la música de las flautas" 5 .

Es elocuente la importancia que poseían los Tlamatini o Amoxhuaques, pues se le considera verdaderos depositarios y guardianes de la cultura náhuatl. De igual manera, la notable relevancia de los códices, los conocimientos y las artes, revelan el fundamental rol que se le asignaba al resguardo de la memoria colectiva. Cuan transcendental era el papel que cumplían los sabios que en las circunstancias del relato se llevan consigo lo más vital de la cultura al marchar, otra estrofa lo deja dramáticamente claro así:

"Brillará el Sol, amanecerả?

¿Cómo irán, cómo se establecerán los macehuales (pueblo)?

Porque se ha ido, porque se han llevado

la tinta negra y roja (los códices).

¿Cómo existirán los macehuales?

¿Cómo permanecerá la tierra, la ciudad?

¿Cómo habrá estabilidad?

¿Qué es lo que va a gobernarnos?

¿Qué es lo que nos guiará?

¿Qué es lo que nos mostrará el camino?

¿Cual será nuestra norma?

¿Cual será nuestra medida?

¿Cual será el dechado?

¿De donde habrá que partir?

¿Qué podrá llegar a ser la tea y la luz?.

5 Informantes de Sahagún. Op. Cit. Fol 191 v. y 192 r. Citado en León Portilla, M.: Los Antiguos Mexicanos a través de sus crónicas y cantares. Cap. II, Pág. 50.

6 Ibidem. Pág. 51 
La partida de los sabios deja un espacio imposible de llenar, es casi un salto a la nada, es como una condena a los que se quedan pues se han ido los que mantenían viva la cultura. Por eso las interrogantes que son lanzadas al aire respecto de la política, el gobierno, las leyes que los regirán, en definitiva hasta la propia existencia queda en duda. Llama la atención en el contenido de estos poemas el sentido de lamentación que posee por la partida de los sabios, y en particular porque con ellos se van los códices junto a la tinta negra y roja, elementos tan prácticos como simbólicos en la confección de sus registros.

Aunque se trata de una frase ya gastada, los nahuas tenían conciencia de que una nación sin historia era un pueblo sin rumbo. De allí el significado que poseian esta personas claves en la sociedad náhuatl por medio de oficios orientados a la preservación del pasado. En este contexto, es posible advertir el inestimable valor de los códices, contenedores de la voluntad de los antiguos mexicanos por comunicarnos su admirable pasado. Al respecto y como otra evidencia del interés por conservar y trasmitir lo que fueron, Fernando Alvarado Tezozómoc, cronista descendiente de la nobleza azteca, incluyó en su Crónica Mexicáyotl escrita a principios del siglo XVII un texto que nos acerca a la preocupación descrita. Vease parte de él:

"Asi lo vinieron a decir, así lo asentaron en su relato, y para nosotros lo vinieron a dibujar en sus papeles los viejos, las viejas.

Eran nuestros abuelos, nuestras abuelas, nuestros bisabuelos, nuestras bisabuelas, nuestros tatarabuelos, nuestros antepasados, se repitió como un discurso su relato, nos lo dejaron, y vinieron a legarlo a quienes salimos de ellos.

Nunca se perderá, nunca se olvidará, lo que vinieron a hacer, lo que vinieron a asentar en las pinturas: su renombre, su historia, su recuerdo. Así en el porvenir jamás perecerá, jamás se olvidará, siempre lo guardaremos...?

\section{CÓDICES PREHISPÁNICOS E HISPÁNICOS: dos ejemplos.}

A la hora de clasificar y ordenar los códices mesoamericanos, los especialistas lo han hecho según varios criterios. José Alcina Franch nos presenta un panorama al respecto y establece que se han clasificado según su contenido, su origen geográfico, por etnias, por culturas o según la época ${ }^{8}$. Fuera cual fuese la óptica para esto, lo que es claro es la existencia de piezas confeccionadas antes de la llegada de los españoles siendo puramente indigenas, y aquellas realizadas después de la llegada de los peninsulares con evidente influencia europea, pero conservando en substancia la técnica artesanal y artística primitiva, además de contenidos e inspiraciones con base autóctona.

Uno de los considerados prehispánicos y por tanto indígenas, es el Códice Borbónico. Es el más completo de los cinco que existen referentes a las ceremonias que los cronistas describen por cada una de las dieciocho divisiones del año ${ }^{9}$. Debe su denominación al lugar en donde fue

Tezozómoc, F. Alvarado. Crónica Mexicáyotl. Citado en León Portilla, Los Antiguos Mexicanos a través de sus crónicas y cantares. Cap. II, Págs 74-75.

$8 \quad$ Alcina F., José. Op. Cit. Págs. 70-76.

- Sejourné, Laurette. El pensamiento náhuatl cifrado por los calendarios. Siglo XXI. México, 1983. pp. 151-170. 
descubierto en Europa en el siglo XIX, esto es la Bibliotéque del Palais Bourbon de Paris. Si bien se sabe que en el siglo XVIII se encontraba en el Monasterio del Escorial, al parecer fue sacado de allí por las tropas napoleónicas en 1808 y depositados posteriormente en la biblioteca parisina citada $^{10}$

Aunque hay autores que manifiestan que seria una pieza hecha dentro del periodo hispáni$\mathrm{co}$, no obstante la mayor parte de las opiniones autorizadas afirman que es anterior. Una característica que parece confirmar esto último, sería el hecho de que el material de sus 36 folios es de papel indigena.

De acuerdo a Alcina Franch, este manuscrito se le considera como de carácter calendáricoritual, es decir, correspondiente a una pieza cuyo contenido y diseño obedeció a cuestiones de orden místico-religiosa, pues determinaba en el tiempo los dias con las ceremonias y fiestas pertinentes. Dividido en cuatro secciones o partes, las 20 primeras páginas corresponden a un Tonalamatl o calendario de 260 dias, considerando las divinidades propiciatorias y los signos de los señores de los días ( 9 señores de la noche y 13 volátiles). La parte segunda, muestra los nexos de los 9 señores de la noche y los portadores de los dias de período de 52 años. La tercera, es un calendario de 18 veintenas con su festividades y, por último, la cuarta parte repite las fiestas mensuales y continúa con festejos anuales para un período de 52 años ${ }^{11}$.

El que los antiguos nahuas volcaran en calendarios sus actividades rituales, revela el fuerte carácter mistico de la vida cotidiana. En opinión de Jacques Soustelle, el general de las escrituras mesoamericanas presentan una rigurosa

Alcina Franch, J. Op. Cit. Págs. 82-104.

Ibidem. mezcla entre la cronología, los calendarios, la religión y la visión del mundo. Agrega que una parte no poco significativa de los manuscritos o códices del valle de México están compuestos por fechas, de referencias a los astros y sus movimientos, al ritual y a las divinidades. Por ello, los grandes códices mexicanos como es el caso del Borbónico, son ante todo Tonalámatl o "libros del destino"12.

Si bien el inicio del uso del calendario se remontaría al Período Formativo es su etapa tardia (600 a.c.), la elaboración de éstos del tipo religioso más sotisficados pudo ser posterior apuntando al período Clásico (300-900 d.c.), tal vez en paralelo a la aparición de los códices y la escritura glífica que recogerían -como en este caso- el ordenamiento del tiempo incluyendo las fiestas religiosas. A raíz de este rasgo, en general se ha calificado a las civilizaciones clásicas mesoamericanas como "cultistas" por haber imprimido a sus obras una gran espiritualidad, en oposición al período siguiente distinguido por una suerte de militarismo ${ }^{13}$,

A pesar de que la mayor parte de los manuscritos nahuas fueron destruídos después de la conquista, aparte del Borbónico pudieron sobrevivir otros notables códices como el Borgia, el Fejérvary-Mayer y el Cospi, teniendo todos en común el carácter sagrado dado que trataban el calendario-ritual, la adivinación, las ceremonias y comentarios sobre las deidades y el cosmos ${ }^{14}$.

Como una pieza representativa para el período hispánico, se encuentra el caso del Códice Florentino. Alcina Franch expresa que esta

\footnotetext{
2 Soustelle, Jacques. Los Olmecas. Fondo de Cultura Económ. México, 1979. Pág. 160.

13 Silva, Osvaldo. Prehistoria de América. Edit. Univerist. Santiago de Chile, 1990. Parte II, Pág. 80.

14 Soustelle, Jacques. El Universo de los Aztecas. Fono de Cultura Económica. México, 1979. Cap. II, Paf. 45.
} 
reedición de la obra de Sahagún, manuscrito de tres volúmenes distribuídos en doce libros con más de mil doscientos folios y unas 1.800 ilustraciones, habría sido elaborado entre los años 1575 a 1580 . Más tarde fue llevado a Madrid por su patrocinador Fray Rodrigo de Sequera con el fin de que el Rey lo conociera. Posteriormente, habría sido llevado a Roma para su vista en la $\mathrm{Cu}$ ria Vaticana y de allí a la Biblioteca MediceaLaurentiana de Florencia, lugar en donde hoy permanece ${ }^{15}$.

Este códice, a juzgar por sus características y antecedentes puede ser considerado del tipo histórico-artístico, pues su fisonomía esta definida por series de ilustraciones o pinturas correspondientes al texto náhuatl de los Informantes de Sahagún. Es la historia expresada a través de la pictografía ${ }^{16}$.

Cada uno de los doce libros fue dedicado a algún aspecto particular. Los cinco primeros se pueden clasificar dentro de lo místico-religioso, el sexto y séptimo a la filosofía moral y natural respectivamente, y los restantes - de uno en unoa los señoríos nahuas, a los mercaderes y artesanos, al pueblo, a la historia natural y por último, a la llegada de los españoles. En el postrero de los textos, se intenta resaltar la valentía de los defensores de Tlatelolco frente a la llegada de los europeos, lo que se explica simplemente por el hecho que la mayoría de los Informantes de Sahagún eran originarios de esa ciudad ${ }^{17}$.

Más allá de distinguir o clasificar a los manuscritos y códices nahuas conforme fueran confeccionados en el período prehispánico o hispánico,

Alcina Franch, J. Op. Cit. pp. 115-140.

16 León Portilla, M. Visión de los vencidos. Bibl. Americana. Historia 16. Madrid, 1992. Parte Introducción, Pág. 31. hay un hecho que en el conjunto ofrece lo fundamental; la evidencia a través de estas magníficas piezas representativas de la cultura náhuatl que logra trascender físicamente a los siglos, permitiéndo conocer por su intermedio el esplendor de quienes vivieron en las desconocidas tierras americanas antes de la irrupción europea.

\section{CONCLUSIONES}

La manera en que los antiguos habitantes del valle de México valoraron su pasado y todo lo contenido en él, los llevó a perfeccionar un sistema que les permitiera perpetuarlo. Tenían convicción-al parecer-que las respuestas a los grandes problemas que les afectaban podrían esta en la tradición y en la historia, en lo que sus predecesores les habían heredado. En efecto, nada podía estar al azar, entendían que los hombres estaban sujetos a ciertas normas impuestas por los dioses y la naturaleza. Así, los códices fueron para ellos la institucionalización de la memoria colectiva, quedando resguardados y registrados los eventos más preciados, sus vivencias, su cosmogonía, sus deidades, sus leyes, sus costumbres, en fin, todo aquello que les permitía explicar el sentido de su existencia.

Si bien son los códices inapreciables piezas de arte, son también fiel expresión de la forma en que los antiguos mexicanos se veían a sí mismos, casi como un espejo de sus realidades, sus gentes y su mentalidad.

Aunque resulte evidente afirmarlo, debe destacarse que estos magníficos manuscritos acompañados de dibujos y pinturas, son la constancia más elocuente del alto nivel de desarrollo de la cultura náhuatl. No ignorando en absoluto otras expresiones de ella como lo fue la arquitectura por ejemplo, hay en el conjunto una gran demostración de la inteligencia humana por sus obras.

La "interrupción" producida al desenvolvimien- 
to cultural autóctono por la llegada de los españoles, no impidió que la importancia y significado de los códices fuera transmitido a los conquistadores y asimilado en parte. La historia prehispánica escrita por los mexicanos en sus códices no pudo sobrevivir completamente, pero al menos sus técnicas y formas de registro manejadas por sus herederos derivaron en nuevos manuscritos, verdaderos eslabones de la Historia al permitir concadenar el pasado náhuatl con la nueva etapa bajo dominio europeo.

Para un pueblo que al arribo de Cortés se encontraba viviendo el "Quinto Sol", una apocalíptica época a la que desesperadamente intentaban prolongar alimentando a sus dioses con sangre humana, su historia habia finalizado. Como pocos testimonios de su grandeza y esplendor, los códices representan el pasado náhuatl aun vivo gracias a sus creadores y a quienes hoy se han ocupado de sus misterios.

\section{BIBLIOGRAFIA}

Alcina Franch, José. Códices Mexicanos. Colección MAPFRE Madrid, 1992

León Portilla, Miguel. Los antiguos mexicanos a través de sus crónicas y cantares. Fondo de Cultura Económica México, 1961

León Portilla, Miguel. Visión de los vencidos. Biblioteca Américana. Historia 16. Madrid, 1992

Sejourne, Laurette. El pensamiento náhuatl cifrado por los calendarios. Edit. Siglo Veintiuno. México, 1983 Silva, Osvaldo. Prehistoria de América. Edit. Universitaria. Santiago de Chile, 1990

Soustelle, Jacques. El universo de los Aztecas. Fondo de Cultura Económica. México, 1979

Soustelle, Jacques. Los Olmecas. Fondo de Cultura Económica. México, 1979. 